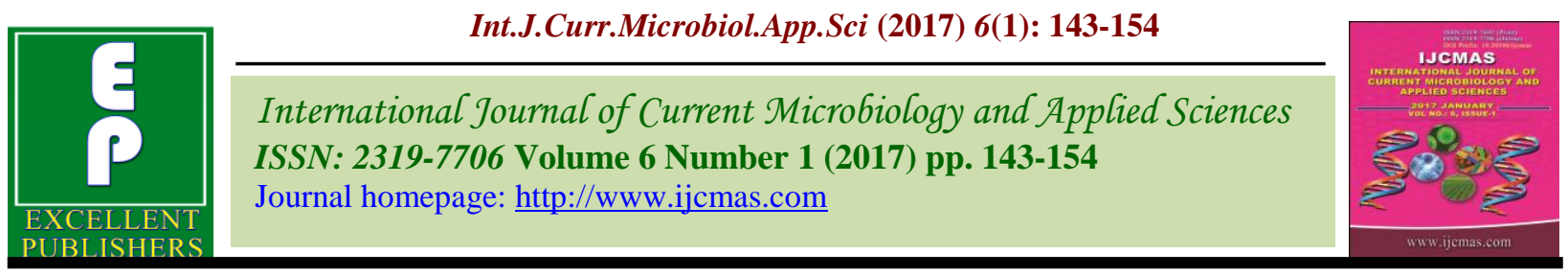

Original Research Article

http://dx.doi.org/10.20546/ijcmas.2017.601.018

\title{
Production, Extraction and Characterization of Red Pigment Produced by Serratia rubidaea JCM 1240T isolated from Soil
}

\author{
R.R. Rakh ${ }^{1}$, S.M. Dalvi ${ }^{2}$, B.B. Musle ${ }^{3}$ and L.S. Raut ${ }^{4}$ \\ ${ }^{1}$ Department of Microbiology, Shri Guru Buddhiswami Mahavidyalaya, \\ Purna (Jn.) Dist. Parbhani, India \\ ${ }^{2}$ Department of Botany, Shri Guru Buddhiswami Mahavidyalaya, \\ Purna (Jn.) Dist. Parbhani, India \\ ${ }^{3}$ Department of Chemistry, Shri Guru Buddhiswami Mahavidyalaya, \\ Purna (Jn.) Dist. Parbhani, India \\ ${ }^{4}$ Department of Microbiology, Sant Tukaram College, Parbhani, Dist. Parbhani, India \\ *Corresponding author
}

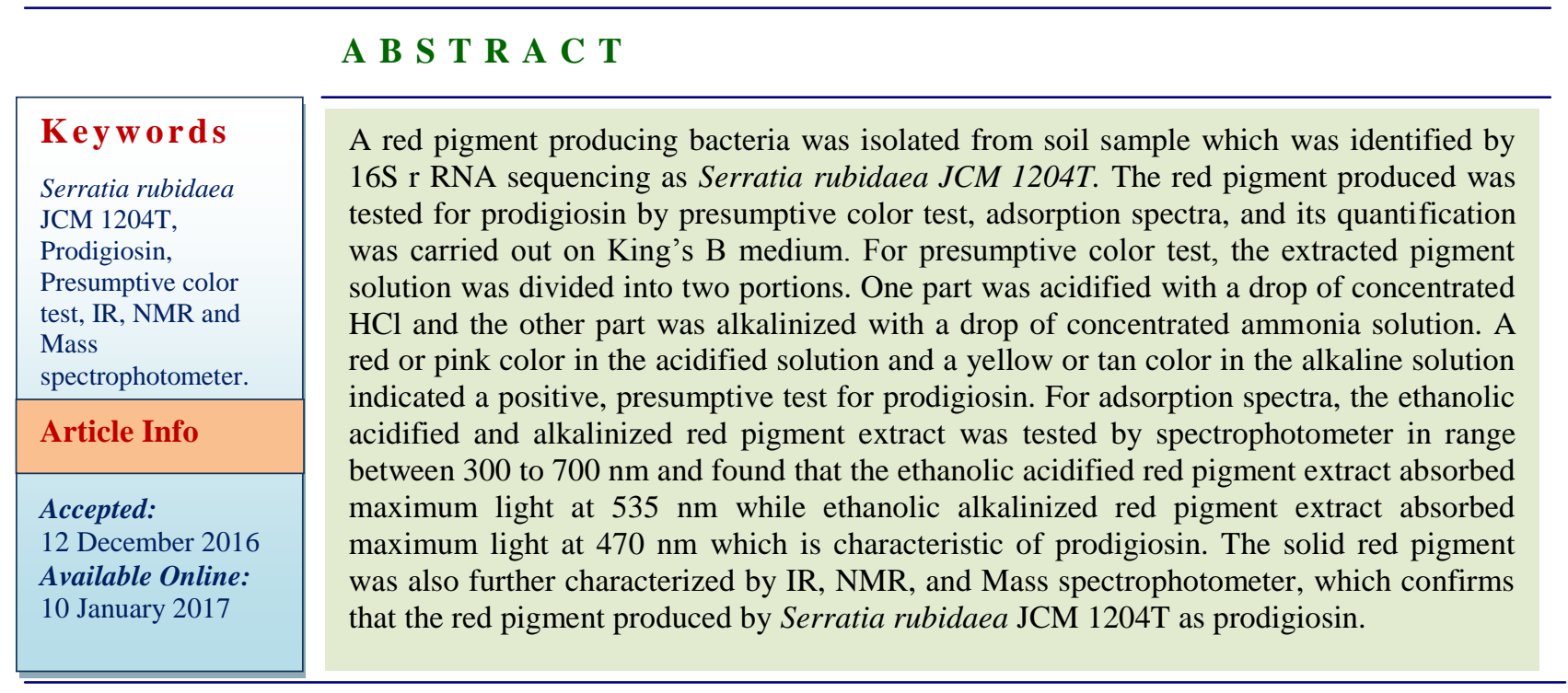

\section{Introduction}

Many artificial synthetic colorants, which have widely been used in foodstuff, dyestuff, cosmetic and pharmaceutical manufacturing processes, comprise various hazardous effects. To counter act the ill effect of synthetic colorants, there is worldwide interest in process of development for the production of pigments from natural sources. The utilization of natural pigments in foodstuff, dyestuff, cosmetic and pharmaceutical manufacturing processes has been increasing in recent years thanks to the knowledge about the harmful effects of synthetic pigments and their industrial byproducts on humans and the environment (Unagul et al., 2005; Chidambaram and Lakshmanaperumalsamy, 2009).

Natural pigments can be obtained from two major sources, plants (Mizukami, et al., 1978; Papageorgiou et al., 1979) and microorganisms (Cross and Edinberry, 1972; Ryu et 
al., 1989; Parisot et al., 1990; Yongsmith et al., 1994; Kim et al., 1998a, and Cho et al., 2002). Biopigments from the microorganisms have been preferred over those from plants because of their stability (Raisainen et al., 2002) and the availability of their cultivation technology (Kim et al., 1999; Parekh et al., 2000) throughout the year. On the other hand, biopigments from plants have numerous drawbacks like instability against light, heat or adverse $\mathrm{pH}$, low water solubility and often non-availability throughout the year (Chandni et al., 2012).

One of the studied biopigments of microbial origin is the prodigiosin. Prodigiosin (PDG) is a natural red pigment characterized by a common pyrrolylpyrromethane skeleton, having low molecular weight (323.4 Dalton), appearing only in the late stages of bacterial growth as secondary metabolite (Harris et al., 2004) and produced by many bacterial species, including many strains of Serratia marcescens, Hahella chejuensis, Streptomyces variegatus, Colwellia (Vibrio) psychrerythraea, "Pseudomonas magnesiorubera, and other eubacteria (Yamamoto et al., 1999). The prodiginine group, of which prodigiosin is a member, is a group of structural isomers that contain a tripyrrole core with different alkyl chains, have no defined role in the physiology of producing strains but have been reported to have antifungal, antibacterial, algicidal, antiprotozoal, antimalarial, immunosuppressive, anticancer and antiproliferative activities (Castro, 1967; Boger and Patel, 1988;Williams and Quadri, 1980; Demain, 1995; Han et al., 1998;Cerdeno et al., 2001; Furstner, 2003; Montaner and Pe'rez-Toma's 2003and Samrot et al., 2011).

According to a recent report, prodigiosin or its analogues have been considered effective biological control agents against harmful algae (Jeong et al., 2005; Nakashima et al., 2006) have been considered cell growth regulators (Haddix et al., 2008) and can be used as a natural dye (Alihosseini, et al., 2008).

The present investigation focuses on i) Identification of red pigment producing bacteria by $16 \mathrm{~S}$ rRNA Sequencing ii) Test the red pigment produced by the red bacteria for prodigiosin by presumptive color test and adsorption spectra, and iii) confirmation red pigment as prodigiosin by IR, NMR and Mass spectrophotometer.

\section{Materials and Methods}

\section{Isolation of Red Pigment Producing bacteria from Soil}

Soil samples, for isolation of red pigment producing bacteria, were collected from different field and brought in poly-ethylene bags to the laboratory, Department of Microbiology, Shri Guru Buddhiswami Mahavidyalaya, Purna.

The collected soil samples were serially diluted and plated on King's B agar plates. Red-pigmented colonies were isolated on the plates after incubation and preserved at $4^{\circ} \mathrm{C}$. The isolated red pigmented bacteria were identified by $16 \mathrm{~S} r$ RNA gene sequence analysis carried out commercially from Agharkar Research Institute, Pune.

\section{Presumptive color tests for prodigiosin}

Red pigment produced in suitable medium was presumptive tested (Gerber and Lechevalier, 1976) for prodigiosin. For presumptive test, pigmented broth was suspended overnight in $95 \%$ ethanol at 22 to $24^{\circ} \mathrm{C}$. Debris was removed from the suspension by centrifugation at 5,000 rpm for $15 \mathrm{~min}$. The clear solution was then divided into two portions. One part was acidified with a drop of concentrated $\mathrm{HCl}$ and the other part was alkalinized with a drop of concentrated 
ammonia solution. A red or pink color in the acidified solution and a yellow or tan color in the alkaline solution indicative of a positive presumptive test for prodigiosin.

\section{Determination of adsorption spectra}

For determination of absorption spectra, Gerber and Lechevalier, (1976) method was used. Pigmented bacteria were treated with ethanol, and the cell debris in the suspensions was removed by centrifugation at 5,000 rpm for $15 \mathrm{~min}$.

Samples $(1 \mathrm{ml})$ of the ethanol extracts were acidified or alkalinized with $0.1 \mathrm{ml}$ of $1 \mathrm{~N}$ HCI or $1 \mathrm{~N} \mathrm{NaOH}$, respectively. The absorbance spectrum of sample was measured with a Single Beam UV - Visible Spectrophotometer (Bioera Life Science Pvt. Ltd.) in the range of 300 to $700 \mathrm{~nm}$. Acidified or alkalinized $95 \%$ ethanol was used as a blank.
Production of Prodigiosin in suitable Medium and Quantification of prodigiosin

In order to determine the suitable media supporting the maximal production of prodigiosin, red pigment producing bacteria was grown in Nutrient Broth, and King's B Broth, at $25{ }^{\circ} \mathrm{C}$. The levels of prodigiosin in these conditions were estimated after $24 \mathrm{hr}$, 48hr, $72 \mathrm{hr}$ and $96 \mathrm{hr}$.

For quantification of prodigiosin produced, bacterial cell absorbance in the King's broth and Nutrient broth was measured at $620 \mathrm{~nm}$, following which the broth suspensions were subjected to centrifugation at $5000 \mathrm{rpm}$ for 15 min to collect the cell pellet. $10 \mathrm{ml}$ of $95 \%$ methanol was added to the cell pellet and centrifuged under the same condition. 95\% methanol was used as a blank. Methanolic extract of prodigiosin showed characteristic maxima at $499 \mathrm{~nm}$. Extracted prodigiosin was estimated using the following equation (Mekhael and Yousif, 2009).

[OD499-(1.381 x OD620)] x 1000

Prodigiosin unit/cell =

Where,

OD499 - pigment absorbance;

OD620 - bacterial cell absorbance

1.381 - constant

\section{Extraction and Characterization of Red pigment}

Serratia rubidaeagrown in King's B broth was centrifuged at $10000 \mathrm{rpm}$ for 20 minutes and the cell pellet was collected. The pigment from the cell pellet was extracted with acidified methanol (1N HCl 1ml: Methanol $24 \mathrm{ml}$ ) and the extract was centrifuged at $5000 \mathrm{rpm}$ for 15 minutes. The supernatant was concentrated in Rota evaporator at $60{ }^{\circ} \mathrm{C}$ to obtain crude pigment. The crude concentrated pigment was recrystallized with methanol (Min - Jung - Song et al., 2005; Chandrashekhar et al., 2012).

The chemical structure of the purified pigment was characterized by FTIR BRUKER model RXI Spectrometer, mass spectrometry and NMR (Bruker, Germany). IR Spectra of prodigiosin was scanned on FTIR BRUKER model RXI Spectrometer. 
${ }^{1}$ HNMR spectra were recorded in DMSO on Gemini $200 \mathrm{MHz}$ instrument using TMS as an internal standard (chemical shift given in $\delta$ $\mathrm{ppm}$ ). The mass spectrum was recorded on Cintra - 15-GCMS - Spectrophotometer.

\section{Result and Discussion}

\section{Isolation of Red Pigment producing bacteria from Soil}

Serially diluted soil samples plated on king's B agar plates produced wide range of red pigmented colony. Out of these colonies, a red pigment colony was selected whose pigment was to be tested for prodigiosin, isolated on the plates after incubation and preserved at $4^{\circ} \mathrm{C}$. Later on the isolated red pigmented bacterium was identified by $16 \mathrm{~S} \mathrm{r}$ RNA gene sequence analysis as Serratia rubidaea JCM 1240T (photo plate 3.1) whose phylogenetic relation (Figure 3.2) and partial $16 \mathrm{~S} \mathrm{r}$ RNA gene sequence is as follows (Figure 3.1).

\section{Presumptive color tests for prodigiosin}

For this presumptive test pigmented broth was suspended overnight in $95 \%$ ethanol at 22 to $24^{\circ} \mathrm{C}$. Debris was removed from the suspension by centrifugation at 5,000 rpm for $15 \mathrm{~min}$. The clear solution was then divided into two portions. One part was acidified with a drop of concentrated $\mathrm{HCl}$ and the other part was alkalinized with a drop of concentrated ammonia solution. A red or pink color in the acidified solution was observed while a yellow or tan color in the alkaline solution indicated a positive presumptive test for prodigiosin as shown (photo plate 2).

Similar types of results were also shown in studies carried out by Ming-Jer Ding and Robert P. Williams (1983) where strain of Serratia marcescens isolated from clinic shows a red or pink color in the acidified solution while a yellow or tan color in the alkaline solution. This test indicative for presumptive test for prodigiosin.

\section{Determination of adsorption spectra}

For determination of absorption spectra, pigmented ethanol extracts were acidified or alkalinized with $0.1 \mathrm{ml}$ of $1 \mathrm{~N} \mathrm{HCI}$ or $1 \mathrm{~N}$ $\mathrm{NaOH}$, respectively. The absorbance spectrum of sample was measured with a Single Beam UV - Visible Spectrophotometer (Bioera Life Science Pvt. Ltd.) in the range of 300 to $700 \mathrm{~nm}$. Acidified or alkalinized $95 \%$ ethanol was used as a blank.

Pigment extracted with ethanol from Serratia rubidaea JCM 1240T showed characteristic maxima of 535 (Figure 3.3) and $470 \mathrm{~nm}$ in acid and alkaline solutions, respectively, which is indicative that the pigment extracted with ethanol was prodigiosin. Similarly, Prodigiosin extracted with ethanol from $S$. marcescens Nima showed characteristic maxima of 535 and $470 \mathrm{~nm}$ in acid and alkaline solutions, respectively (Williams and Qadri, 1980; Ming-Jer Ding and Robert Williams, 1983).

Prodigiosin was reported to display a characteristic absorption spectrum in ethanol, with a maximum at $534 \mathrm{~nm}$ (Slater et al., 2003) and single peak absorbance at $535 \mathrm{Nm}$ (Giri et al., 2004; Song et al., 2006; Montaner et al., 2000) extracted prodigiosin by shaking the S. marcescens 2170 cells with a mixture of methanol/1N HCl in the ratio 24:1.

Absorption spectrum of the pigment produced by Serratia rubidaea JCM was dependent on $\mathrm{pH}$ value similar to that reported earlier (Song et al., 2006). Thus at $\mathrm{pH} 2.0$, the pigment was red and showed a maximum absorption at 535 $\mathrm{nm}$, which is identical to that of prodigiosin hydrochloride. Under neutral condition $(\mathrm{pH}$ 7.3), its absorption intensity decreased and the colour of the pigment changed to pink. 
However, in alkaline condition $(\mathrm{pH} 10.0)$ the colour was orange and its absorption spectrum shifted to $470 \mathrm{~nm}$. Pigment produced by Serratia rubidaea JCM 1240T recorded maximum absorption at and $470 \mathrm{~nm}$ in acid and alkaline solutions, respectively suggesting that this pigment is prodigiosin.

Production of Prodigiosin in suitable Medium and Quantification of prodigiosin

To determine suitable medium for production and quantification of prodigiosin,Serratia rubidaea JCM 1240T was grown in Nutrient Broth, King's B Broth, at $25^{\circ} \mathrm{C}$.

For quantification of prodigiosin produced, bacterial cell absorbance in the medium was measured at $620 \mathrm{~nm}$, while absorbance of methanolic extract of prodigiosin was measured at $499 \mathrm{~nm}$ (Table 3.1). The concentrations of prodigiosin in these conditions were estimated after $0 \mathrm{hr}, 24 \mathrm{hr}$, $48 \mathrm{hr} 72 \mathrm{hr}$ and $96 \mathrm{hr}$. By using these absorbance, prodigiosin concentration was determined as represented in (Table 3.2).

Table.3.1 Pigment Absorbance at 499nm

\begin{tabular}{|l|c|c|}
\hline Hour & Nutrient Broth (O.D.) & King's B Broth (O.D.) \\
\hline $24 \mathrm{hr}$ & 00 & 00 \\
\hline $48 \mathrm{hr}$ & 1.603 & 1.673 \\
\hline $72 \mathrm{hr}$ & 1.654 & 1.686 \\
\hline $96 \mathrm{hr}$ & 1.566 & 1.580 \\
\hline
\end{tabular}

Table.3.2 Total prodigiosin estimated in nutrient broth and King's B broth

\begin{tabular}{|c|c|c|}
\hline Hour & $\begin{array}{c}\text { Prodigiosin in } \\
\text { Nutrient Broth mg/lit }\end{array}$ & $\begin{array}{l}\text { Prodigiosin in } \\
\text { King's B Broth mg/ lit }\end{array}$ \\
\hline $24 \mathrm{hr}$ & 00 & 00 \\
\hline $48 \mathrm{hr}$ & 1070.33 & 1188.94 \\
\hline $72 \mathrm{hr}$ & 1055.96 & 1246.10 \\
\hline $96 \mathrm{hr}$ & 885.38 & 957.10 \\
\hline
\end{tabular}

Fig 3.1

ATTTG CCCATG GG CG CAAGCCTG CATGCNG CCATG CCG CG TG TG TGAAG AACG CCTTCG GG TTG TA AAG CACTTTCAG CG AG GAG GAAGG TG GT GANCTT AATACG TTCATCAATTG ACGTTACTCG CAG A AG AAG CACCG G CTAACTCCG TGCCAG CAG CCG CG GTAATACG GAG G GTG CAAG CG TTAATCG GAA TT ACTG GG CGT AAAG CG CACG CCAG GCG GTTTG TTAAG TCANATG TG AAATCCCCG ANCTT AACT T G GG AAC TG CATTTG AAACT G G CAAG CT AG AG TCTCG TATAG G GG G GT AG AATTCCAGG TG TACCG G TG GAAATG CGT ACAAG ATCTGG AGG AATACCGG TGG CGAANG CNG CCCCCCTGG GACNAAAAA CTG ACG CTCATG TGCG AAAG CGTTG GG G AG CAAACCG GAATCACATACCCTG GTCAATCCACG CC CGNTAAACG ATGANCCATTTTGCG GAGG TT GNNGCCCTTNGG AG G CGTGG GNTTCCG NGANCT AA CACTTAAAATCC

F igure 3.1: $16 \mathrm{~S}$ rRNA Gene Sequencing 
Fig 3.2

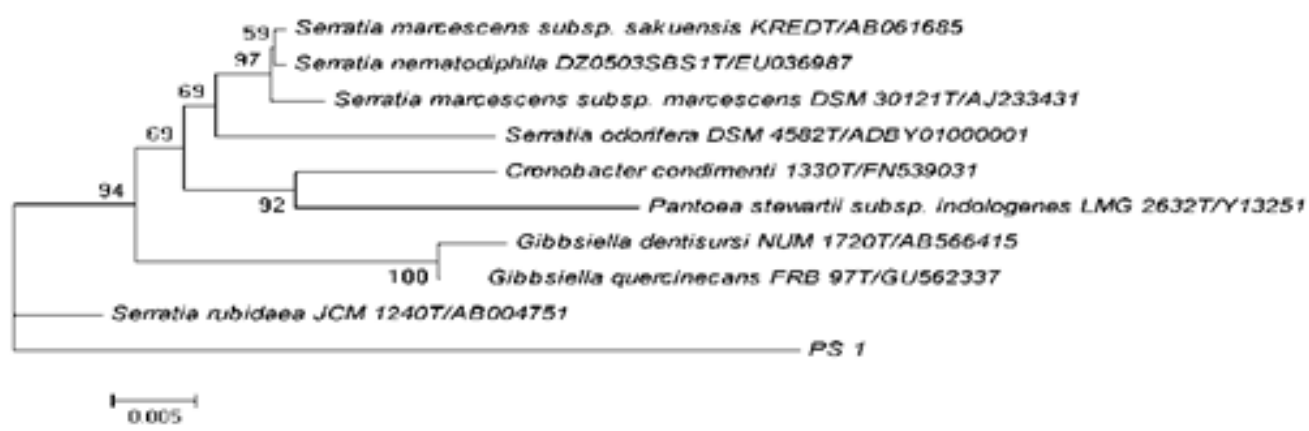

Figure 3.2: Closest Phylogenetic relation of Serratia rubidaea JCM 1240T

Fig 3.3

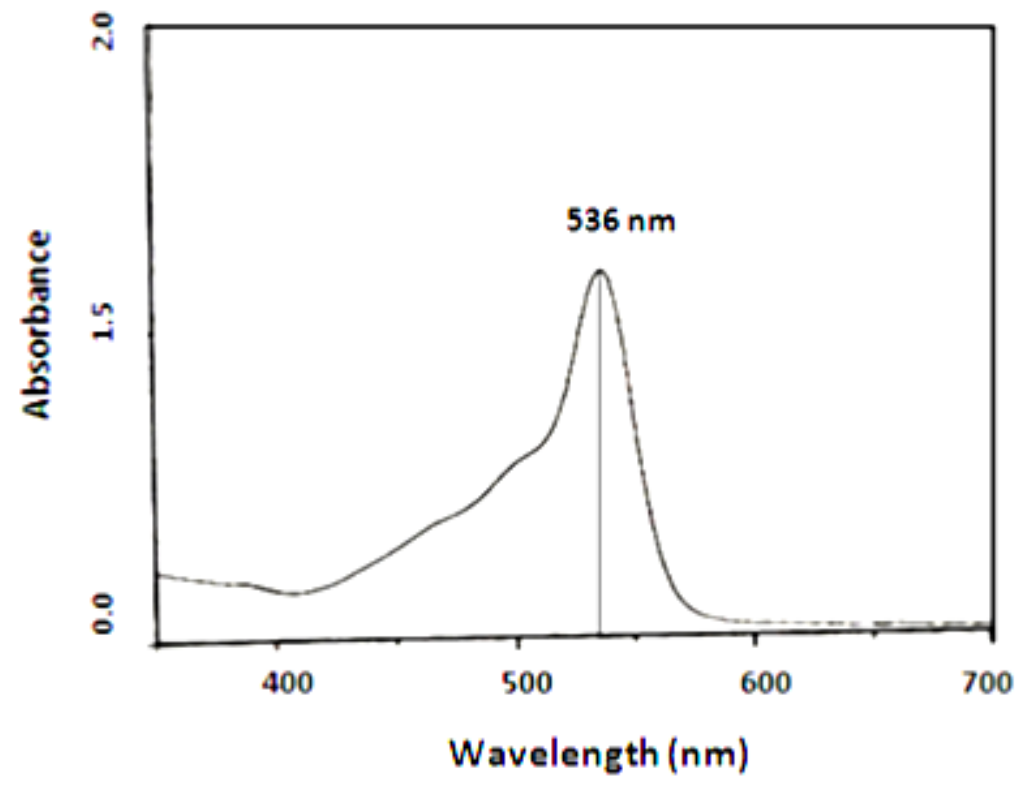

Figure 3.3: Absorption Spectra of Acidified Ethanolic Red

Pigment 
Fig 3.4

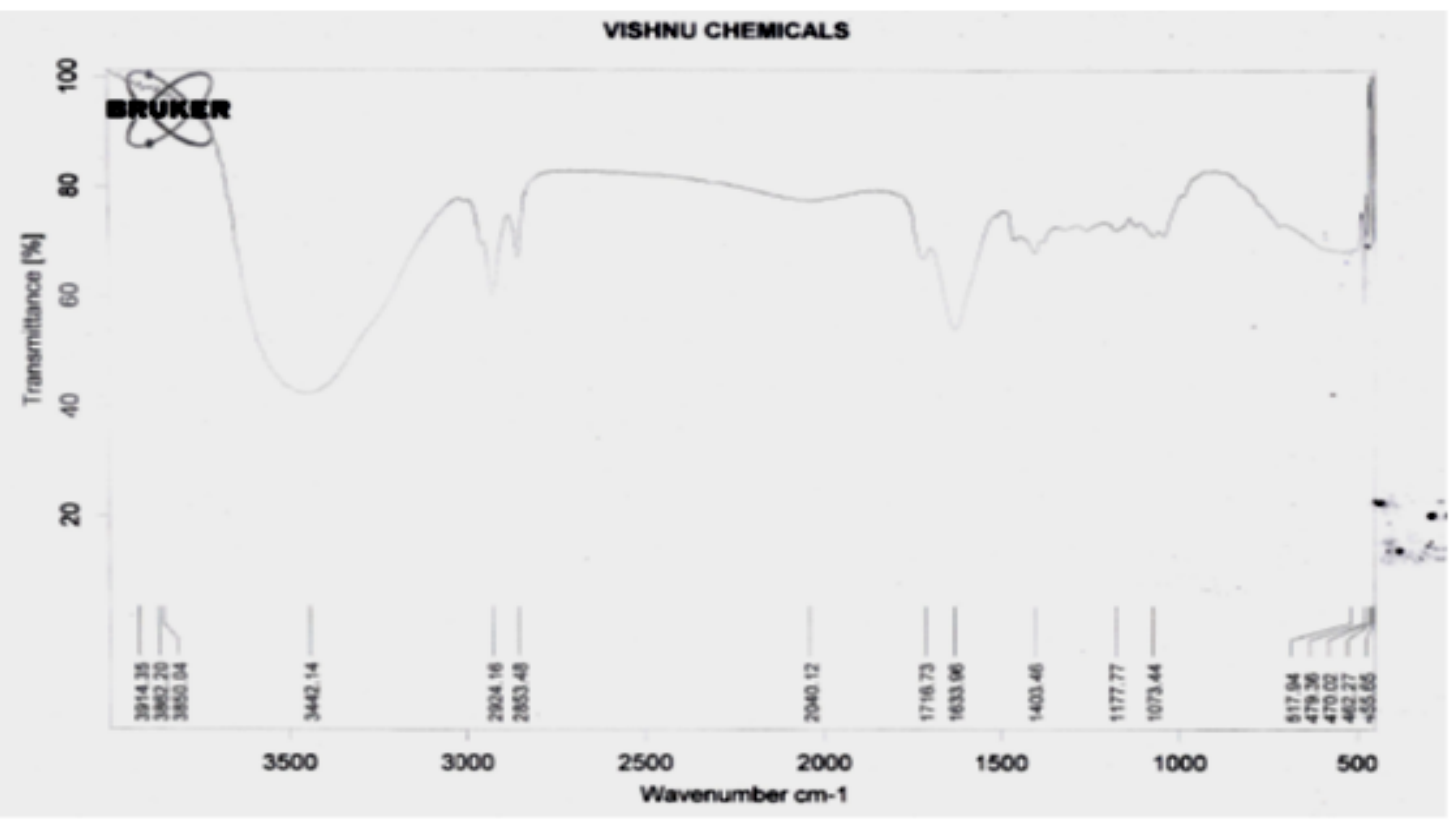

Figure 3.4: IR spectra of purified Prodigiosin from Serratia rubidaea JCM 1240T

Fig 3.5

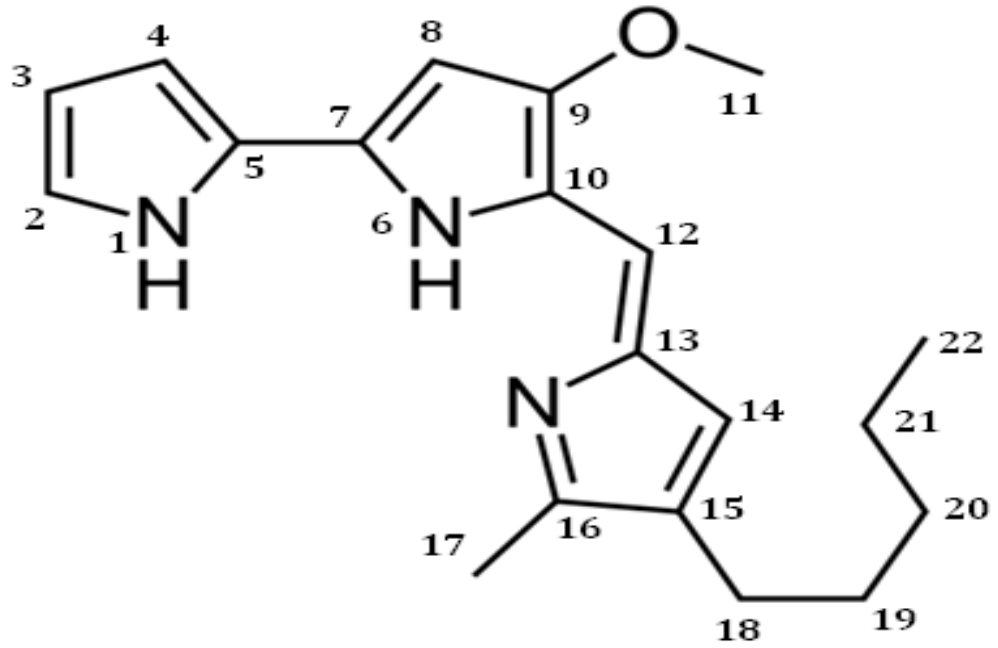

Figure 3.5: Structure of Prodigiosin determined by ${ }^{1}$ HNMR spectra 
Photo 3.1

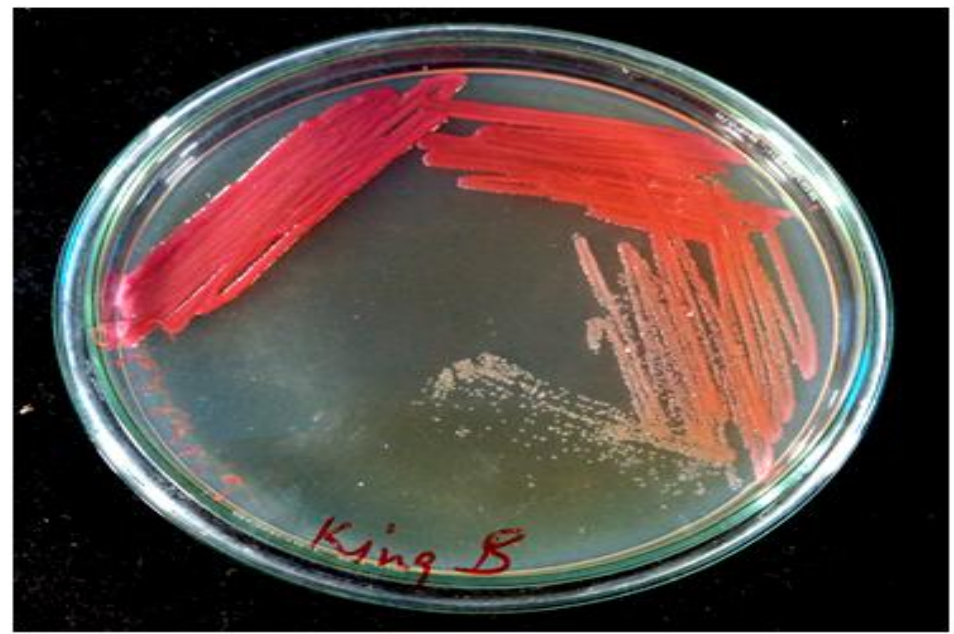

Photo plate 3.1: Isolated Serratia rubidaea JCM $1240 \mathrm{~T}$

on King's B Agar Plate

Photo 3.2

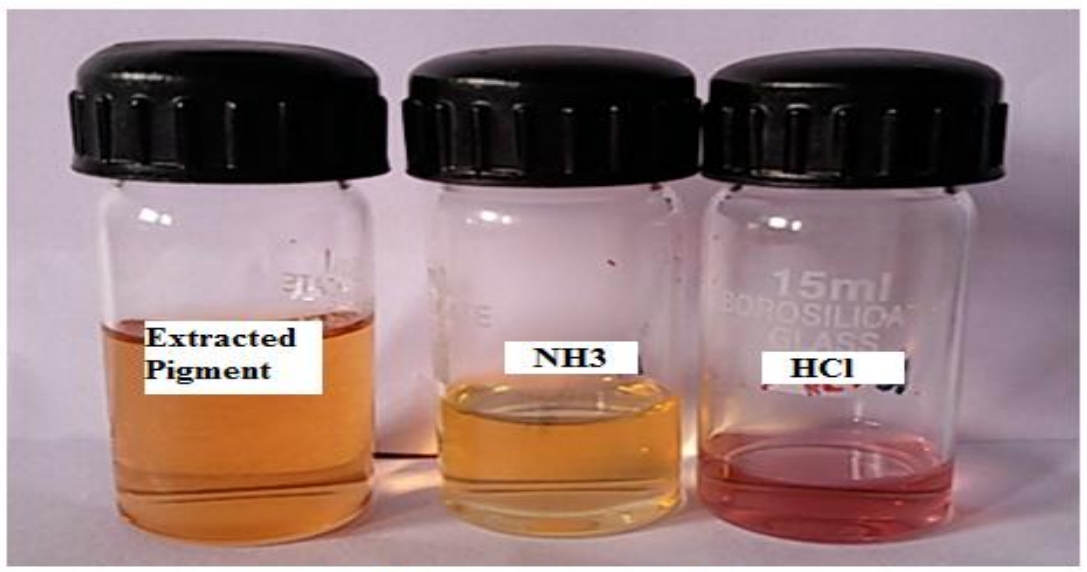

Photo plate 3.2: Presumptive Test for Prodigiosin

Prodigiosin unit per cell after $48 \mathrm{hr}$ was found to be 1070.33 and 1188.94 in nutrient broth and King's B broth respectively. Maximum production was reported in $72 \mathrm{hr}$ thereafter production ceased towards $96 \mathrm{hr}$. The lowest prodigiosin unit per cell was found after $96 \mathrm{hr}$ i.e. in nutrient broth it was 885 and in peptone glycerol broth i.e. 957.1.

Similar results were obtained by Kamble and
Hiwarale (2012) where they compared prodigiosin production in Nutrient Broth and Peptone Glycerol Broth. In this study, they found highest prodigiosin production after 72 $\mathrm{hr}$ in peptone glycerol broth than nutrient broth.

\section{Extraction and Characterization of Red pigment}

The chemical structure of the purified prodigiosin was characterized by FTIR 
BRUKER model RXI Spectrometer, mass spectrometry and NMR (Bruker, Germany). IR Spectra of prodigiosin was scanned on FTIR BRUKER model RXI Spectrometer. ${ }^{1}$ HNMR spectra were recorded in DMSO on Gemini $200 \mathrm{MHz}$ instrument using TMS as an internal standard (chemical shift given in $\delta$ ppm). The mass spectrum was recorded on Cintra - 15 - GCMS - Spectrophotometer.

\section{IR Spectra}

IR Spectra of prodigiosin (Figure 3.4) showed characteristic band at near region $3442.14 \mathrm{~cm}^{-}$ ${ }^{1}$ due to $>N-H$ group (amide gr.), bands at 2924.16 - $2853.48 \mathrm{~cm}^{-1}$ due to $\mathrm{C}-\mathrm{H}(\mathrm{sp} 3)$ stretching vibrations from methyl and Methylene group, bands at near region $1633.96 \mathrm{~cm}^{-1}$ is due to Pyrrole group and the band at $1716.73 \mathrm{~cm}^{-1}$ is due to $\mathrm{C}=\mathrm{C}$ stretching vibrations. The visible peak at $1403.46 \mathrm{~cm}^{-1}$ is due to the presence of $\mathrm{C}-\mathrm{O}$ group in prodigiosin.

Thus from the IR Spectrum the main functional groups that resulted in red pigment were Pyrrole, amide, Methylene, methyl and alkene.

\section{HNMR spectra:}

${ }^{1}$ HNMR spectra of prodigiosin were studied in DMSO, represents the proton peaks corresponding to chemical shifts at $\delta 5.323$ ppm, $\delta 5.053 \mathrm{ppm}, \delta 3.773 \mathrm{ppm}, \delta 2.354 \mathrm{ppm}$, $\delta 1.236 \mathrm{ppm}$, and $\delta 0.853 \mathrm{ppm}$ assigned to the carbon atoms $\mathrm{C} 2, \mathrm{C} 12, \mathrm{C} 11, \mathrm{C} 18, \mathrm{C} 21$, and $\mathrm{C} 22$ based on the ${ }_{1} \mathrm{HNMR}$ spectra structure of prodigiosin presented (Figure 3.5).

\section{Mass Spectra}

The mass spectra for the prodigiosin exhibited correct molecular ion peaks for its molecular weights.

In the present study, the data obtained for the spectroscopic analyses of the red pigment with IR, ${ }^{1} \mathrm{HNMR}$ and Mass spectra very clearly testify that the pigment produced by Serratia rubidaea JCM 1240 T is prodigiosinlike pigment. Sumathi et al., 2014 used same technique to characterize the pigment produced bySerratia marcescens NPLR1 where they found the pigment produced was also prodigiosin.

\section{References}

Alihosseini, F., K.S. Ju, J. Lango, B.D. Hammock, and G. Sun. 2008. Antibacterial colorants: characterization of prodiginines and their applications on textile materials. Biotechnol. Prog., 24: $742-747$.

Boger, D.L., and M. Patel. 1988. Total synthesis of prodigiosin, prodigiosene, and desmethoxyprodigiosin: DielsAlder reactions of heterocyclic azadienes and development of an effective palladium(II)-promoted 2,2_bipyrrole coupling procedure. J. Org. Chem., 53: 1405-1415.

Castro, A.J. 1967. Antimalarial activity of prodigiosin. Nature, 213: 903-904.

Cerdeno, A.M., Bibb, M.J. and Challis, G.L. 2001. Analysis of the prodiginine biosynthesis gene cluster of Streptomyces coelicolorA3(2): new mechanisms for chain initiation and termination in modular multienzymes. Chem. Biol., 8, 817-829.

Chandni Gulani, Sourav Bhattacharya and Arijit Das. 2012. Assessment of process parameters influencing the enhanced production of prodigiosin from Serratia marcescens and evaluation of its antimicrobial, antioxidant and dyeing potentials. Malaysian J. Microbiol., Vol. 8(2), pp. 116-122

Chandrashekhar Naik, Srisevita, J.M., Shusham, K.N., Farah Noorin, Shilpa, A.C., Muttanna, C.D., Darshan, N., 
Sannadurgappa, D. 2012. Peanut Oil Cake: A Novel Substrate for Enhanced Cell Growth and Prodigiosin Production from Serratia marcescens CF -53 . $J$. Res. Biol., 2 (6) : 549 - 557.

Chidambaram Kulandaisamy Venil and Perumalsamy Lakshmanaperumalsamy. 2009. An Insightful Overview on Microbial Pigment, Prodigiosin. Electronic J. Biol., Vol. 5(3): 49-61.

Cho, Y.J., Park J.P., Hwang H.J., Kim, S.W., Choi, J.W., and Yun, J.W. 2002. Production of red pigment by submerged culture of Paecilomyces sinclairii. Lett. Appl. Microbiol., 35: 195-202.

Cross, B.E., and Edinberry, M.N. 1972. Pigments of Gnomonia erythrostoma. Part I. The structures of erythrostominone, deoxyerythrostominone, and deoxyerythrostominol. J. Chem. Soc. Perkin I, 3: 380-390.

Demain, A.L. 1995. Why do microorganisms produce antimicrobials? In Fifty Years of Antimicrobials: Past Perspectives and Future Trends (Society for General Microbiology Symposium no. 53), pp. 205-228. Edited by P. A. Hunter, G. K. Darby \& N. J. Russell. Cambridge: Cambridge University Press.

Furstner, A. 2003. Chemistry and biology of roseophilin and the Prodigiosin alkaloids: A survey of the last 2500 years. Chem. Int. Ed. Engl., 42, 35823603.

Gerber, N.N. and Lechevalier, M.P. 1976. Prodiginine (prodigiosin-like) pigments from Streptomyces and other Actinomyces. Canadian J. Microbiol., 22: 658-667.

Giri, A.V., Anandkumar, N., Muthukumaran, G., Pennathur, G. 2004. A novel medium for the enhanced cell growth and production of prodigiosin from
Serratia marcescens isolated from soil. Biomedical Central Microbiol., 4: 1-10. Haddix, P.L., et al. 2008. Kinetic analysis of growth rate, ATP, and pigmentation suggests an energy-spilling function for the pigment prodigiosin of Serratia marcescens. J. Bacteriol., 190: 74537463.

Han, S.B., et al. 1998. T-cell specific immunosuppression by prodigiosin isolated from Serratia marcescens. Int.

J. Immunopharmacol., 20: 1-13.

Harris, K.P., Williamson, R., Slater, H., Cox, A., Abbasi, S., Foulds, I., Simonsen, T., Leeper J., and Salmond P.C. 2004. The Serratia gene cluster encoding biosynthesis of the red antibiotic, prodigiosin, shows species and strain dependent genome context variation. Microbiol, 150: 3547-3560.

Jeong, H., et al. 2005. Genomic blueprint of Hahella chejuensis, a marine microbe producing an algicidal agent. Nucleic Acids Res., 33:7066-7073.

Kamble, K.D., and Hiwarale, V.D. 2012. Prodigiosin production from Serratia marcescens strains obtained from farm soil, Int. J. Environ. Sci., Volume 3, No 1, pp $631-638$.

Kim, C.H., Kim, S.W., and Hong, S.I. 1998. Production of red pigment by Serratia sp. KH-95 and its cultural properties. Korean J. Biotechnol. Bioeng., 13: 431437.

Kim, C.H., Kim, S.W., and Hong, S.I. 1999. An integrated fermentation separation process for the production of red pigment by Serratia sp. KH-95. Process Biochem., 35: 485-490.

Mekhael, R., and Yousif, S.Y. 2009. The role of red pigment produced by Serratia marcescens as antibacterial and plasmid curing agent. J. Duhok Univ., 12: 268274.

Min - Jung - Song, Jungdon Bae, Dae Sil Lee, Chnag - Ho Kim, Seung - Wook 
Kim, Suk - In Hong. 2006. purification and characterization of prodigiosin produced by integrated bioreactor from Serratia spp. KH - 95. J. Biosc. Bioeng., $101: 157-161$.

Ming-Jer Ding and Robert P. Williams. 1983. Biosynthesis of Prodigiosin by White Strains of Serratia marcescens Isolated from Patients. J. Clin. Microbiol., vol. 17, No. 3 p. $476-480$.

Mizukami, H., Konoshima, M., and Tabata, M. 1978 Variation in pigment production in Lithospermum erythrorhizon callus cultures. Phytochem., 17: 95-97.

Montaner, B., and R. Pe'rez-Toma's. 2003. The prodigiosins: a new family of anticancer drugs. Curr. Cancer Drug Targets, 3: 57-65.

Montaner, B., Navarro, S., Pique M. Vilaseca M. Martinell, M., Giralt, E., Gil, J. and Perez-Thomas, R., 2000. Prodigiosin from the supernatant of Serratia marcescens induce apoptosis in haematopoietic cancer cell lines, British J. Pharmacol., 131(3), pp 585-593.

Nakashima, T., et al. 2006. Producing mechanism of an algicidal compound against red tide phytoplankton in a marine bacterium -proteobacterium. Appl. Microbiol. Biotechnol., 73:684690.

Papageorgiou V. P., Winkler A., Sagredos A. N., and Digenis G. A. 1979. Studies on the relationship of structure to antimicrobial properties of naphthoquinones and other constituents of Alkanna tinctoria. Planta Med., 35: 56-60.

Parekh S., Vinci, V. A. and Strobel, R. J. 2000. Improvement of microbial strains and fermentation processes. Appl. Microbiol. Biotechnol., 54: 287-301.

Parisot D., Devys M., and Barbier M. 1990. Naphthoquinone pigments related to fusarubin from the fungus Fusarium solani (Mart.) Sacc. Microbios, 64: 3147.

Raisainen, R., Nousiainen, P. and Hynninen, P.H. 2002. Dermorubin and 5chlorodermorubin natural anthraquinone carboxylic acids as dyes for wool. Textile Res. J., 72: 973-976.

Ryu B. H., Park B. G., Chi Y. E., and Lee J. H. 1989. Production of purplish-red pigment in mixed culture of Streptomyces propurpuratus ATCC 21630 and Bacillus sp R-89. Korean J Appl. Microbiol. Bioeng, 17: 327-333.

Samrot, A. V., Chandana, K., Senthilkumar P. and Narendra, K. G. 2011. Optimization of Prodigiosin production by Serratia marcescens SU-10 and evaluation of its bioactivity. Int. Res. J. Biotechnol., (ISSN: 2141-5153), 2(5), 128-133.

Shahitha, S. and K. Poornima. 2012. Enhanced Production of Prodigiosin Production in Serratia Marcescens. J. Appl. Pharmaceutical Sci., 02(08); 138140.

Slater, H., Crow, M., Everson, L. and Salmond, G.P.C. 2003. Phosphate availability regulates biosynthesis of two antibiotics, Prodigiosin and carbapenem, in Serratia via both quorum-sensing-dependentand independent pathways. Mol. Microbiol., 47(2), 303-320.

Song, M.J., Bae, J., Lee, D.S., Kim, C.H., Kim, J.S., Kim, S.W., Hong, S.I. 2006. Purification and characterization of prodigiosin produced by integrated bioreactor from Serratia sp. KH-95. J. Biosci. Bioeng., 101: 157-161.

Unagul, P., Wongsa, P., Kittakoop, P., Intamas, S., Srikiti-Kulchai, P., Tanticharoen, M. 2005. Production of red pigments by the insect pathogenic fungus Cordyceps unilateralis $\mathrm{BCC}$ 1869. J. Ind. Microbiol. Biotechnol., 32: 135-140. 
Williams, R.P. and Quadri, S.M. 1980. The pigments of Serratia. In The Genus Serratia, pp. 31-75. Edited by A. Von Graevenitz \& S. J. Rubin. Boca Raton, FL: CRC Press Inc.

Yamamoto, C., et al. 1999. Cycloprodigiosin hydrochloride, a new $\mathrm{H}(+) / \mathrm{Cl}(-)$ symporter, induces apoptosis in human and rat hepatocellular cancer cell lines in vitro and inhibits the growth of hepatocellular carcinoma xenografts in nude mice. Hepatol., 30: 894-902.

Yongsmith, B., Krairak, S., and Bavavoda, R. 1994. Production of yellow pigments in submerged culture of a mutant of Monascus sp. J. Ferment. Bioeng., 78: 223-228.

\section{How to cite this article:}

Rakh, R.R., S.M. Dalvi, B.B. Musle and Raut, L.S. 2017. Production, Extraction and Characterization of Red Pigment Produced by Serratia rubidaea JCM 1240T isolated from Soil. Int.J.Curr.Microbiol.App.Sci. 6(1): 143-154. doi: http://dx.doi.org/10.20546/ijcmas.2017.601.018 